\title{
Letter on A Study on the Effective Ratio of Fat to Stromal Vascular Fraction for Cell-Assisted Lipotransfer
}

\author{
Zuguang Hua $^{1} \cdot$ Peng Wei $^{1}$
}

Received: 4 February 2020/Accepted: 5 February 2020/Published online: 9 March 2020

(C) Springer Science+Business Media, LLC, part of Springer Nature and International Society of Aesthetic Plastic Surgery 2020

Level of Evidence $V$ This journal requires that authors assign a level of evidence to each article. For a full description of these Evidence-Based Medicine ratings, please refer to the Table of Contents or the online Instructions to Authors www.springer.com/00266.

Sir,

We read with great interest the article entitled "A Study on the Effective Ratio of Fat to Stromal Vascular Fraction for Cell-Assisted Lipotransfer" by Bae et al. [1] in Aesthetic Plastic Surgery. In this article, the authors conducted an in vivo study on the effective ratio of fat to stromal vascular fraction (SVF) for cell-assisted lipotransfer (CAL). They concluded that solely fat grafting is the most effective when the amount of fat tissue is limited. For adequate resource of fat tissue, a fat-to-SVF ratio of $1: 1$ is more recommended.

Clinically, the effectiveness of CAL is controversial $[2,3]$. We think that the conclusion of this study may not be directly applied for clinical practice, because the recipient of mice in this study is different from the human condition.

In this study, the grafts were harvested at 8 weeks, and the volume and weight were measured to evaluate graft outcome. We recommend further evaluation of graft viability such as immunostaining for perilipin and CD31 to assess the viable adipocytes and vascularity, since volume or weight does not necessarily correspond to graft viability.

\section{Compliance with Ethical Standards}

Conflict of interest The authors declare that they have no conflicts of interest to disclose.

Human and Animal Rights This article does not contain any studies with human participants or animals performed by any of the authors.

Informed Consent For this type of study informed consent is not required.

\section{References}

1. Bae YC, Kim KH, Yun HJ et al (2020) A study on the effective ratio of fat to stromal vascular fraction for cell-assisted Lipotransfer. Aesthetic Plast Surg 44(1):162-167

2. Chiu CH (2019) Does stromal vascular fraction ensure a higher survival in autologous fat grafting for breast augmentation? A volumetric study using 3-dimensional laser scanning. Aesthetic Surg J 39(1):41-52

3. Kølle SF, Fischer-Nielsen A, Mathiasen AB et al (2013) Enrichment of autologous fat grafts with ex-vivo expanded adipose tissue-derived stem cells for graft survival: a randomised placebocontrolled trial. Lancet. 382(9898):1113-1120

Publisher's Note Springer Nature remains neutral with regard to jurisdictional claims in published maps and institutional affiliations.
Zuguang Hua

hzg-m2004@126.com

1 Ningbo No 1 Hospital, No. 59, Liuting Street, Haishu District, Ningbo 315000, Zhejiang, People's Republic of China 